СЕЛЕКЦИОННЫЕ,

АГРОБИОЛОГИЧЕСКИЕ

И БИОХИМИЧЕСКИЕ

ОСОБЕННОСТИ НЕКОТОРЫХ

ЭЛИТНЫХ ГИБРИДНЫХ ФОРМ ВИНОГРАДА

ТЕХНИЧЕСКОГО НАПРАВЛЕНИЯ СЕЛЕКЦИИ АЗОС

Горбунов Иван Викторович

канд. биол. наук

научный сотрудник

лаборатории виноградарства

и виноделия

Анапская зональная опытная станция виноградарства и виноделия - филиал

Федерального государственного

бюджетного научного учреждения

«Северо-Кавказский федеральный

научный иентр садоводства,

виноградарства, виноделия»,

Анапа, Россия

В данной статье показаны результаты актуальнейшей в настоящее время селекционной работы по выведению новых сортов винограда технического направления и выделению элитных форм, поскольку существует недостаток сортов технического направления использования в сортименте винограда. Важно, наряду с аборигенными, также создавать и выращивать новые технические сорта, сочетающие высокое качество продукции и адаптацию к абиотическим и биотическим стрессовым факторам - показатели, необходимые для выработки оригинальных вин, с высоким уровнем сахаронакопления. Изучение этого вопроса для Анапо-Таманской зоны представляет большой интерес. В результате проведенной научно-исследовательской работы по изучению комплекса хозяйственно ценных селекционных признаков у элитных гибридных форм винограда технического направления среднего и позднего сроков созревания позволило выявлен ряд

\section{BREEDING, AGRO-BIOLOGICAL AND BIOCHEMICAL CHARACTERISTICS OF GRAPE TECHNICAL HYBRID FORMS OF ANAPA'S ZONAL EXPERIMENTAL STATION BREEDING}

Gorbunov Ivan Viktorovich

Cand. Biol. Sci.

Research Associate

of Viticulture and Wine-making Laboratory

Anapa Zonal Experimental Station of Viticulture and Wine-making Branch of $«$ Federal State Budgetary Scientific Institution «North-Caucasus Federal Scientific Center of Horticulture, Viticulture, Wine-making», Anapa, Russia

This article presents the results of the most relevant now breeding work on the creation of new grape technical varieties and the selection of elite forms, since there is a shortage of technical grapes in the assortment. It is important with the indigenous varieties to create and cultivate the new technical varieties that combine the high quality of products with adaptability to abiotic and biotic stress factors - the characteristics are necessary for the production of original wines, with a high level of sugar accumulation. The study of this problem for the Anapo-Taman zone is of great interest. As a result of research work on the study of a complex of economically valuable breeding traits for elite hybrid grape forms of technical purposefulness of middle and late ripening a number of features are revealed: an elite hybrid form III-59-24 stands out among 
особенностей: элитная гибридная форма III-59-24 выделяется среди остальных исследуемых форм по среднему урожаю ягод с куста (при относительно небольшом среднем количестве плодоносных побегов на кусте) 8,1 кг, а также по высоким коэффициентам плодоношения и плодоносности - 1,1 при низкой кислотности ягод - 5,7 г/дм³; элитная гибридная форма III-62-24 отличается средней урожайностью с куста $-8,2$ кг, высоким коэффициентом плодоносности 1,1, высоким содержанием сахара в ягодах 20,1 г/100 $\mathrm{cm}^{3}$; элитная гибридная форма K-I-74-1 обладает самыми крупными гроздями, наибольшей урожайностью с одного куста в среднем в сравнении с остальными исследуемыми формами, высокой концентрацией сахара в ягодах, наибольшей плодоносностью одного побега, а также массой грозди.

Ключевые слова: ВИНОГРАД, СЕЛЕКЦИЯ, СКРЕЩИВАНИЕ, ЭЛИТА, ГИБРИДНАЯ ФОРМА the other of the studied forms by the average yield of berries from the bush (taking into account the relatively small average number of fruiting shoots on the bush) $-8,1 \mathrm{~kg}$, with high fruiting and fruitfulness ratios 1,1 , low acidity of berries $-5,7 \mathrm{~g} / \mathrm{dm}^{3}$; the elite hybrid form III-62-24

is characterized by an average yield from the bush of $8.2 \mathrm{~kg}$, a high fruit bearing coefficient of 1.1 , a high sugar content in the berries of $20,1 \mathrm{~g} / 100 \mathrm{~cm}^{3}$; the elite hybrid form of K-I-74-1 has the largest bunches, the highest yield from one bush in comparison with the other studied forms, a high concentration of sugar in berries, the largest fruitiness of one shoot as well as the big mass of the bunch.

Key words: GRAPES,

BREEDING, CROSSING, ELITE, HYBRID FORM

Введение. Практические успехи селекции за последние годы свидетельствуют об имеющемся потенциале повышения продуктивности сортов растений [1]. Однако идеальных сортов нет в производстве. Исходя из этого, в селекции очень важно совместить в одном генотипе высокий потенциал продуктивности с широкой экологической пластичностью, получить сорт для каждой агроэкологической зоны возделывания.

Характерной особенностью винодельческой продукции является богатство её типов и марок вин, что обусловлено спецификой сортов винограда, технологией приготовления, а также местными природноклиматическими условиями, отличающимися большим разнообразием [2]. В настоящее время всё большую популярность завоёвывают отечественные сорта винограда технического направления, устойчивые к морозу, болезням и вредителям [3].

Основной задачей в селекции винограда на современном этапе является создание сортов винограда с коротким периодом вегетации, устойчи- 
вых к абиотическим (морозы, заморозки, засуха) и биотическим (возбудители болезней, вредители) факторам среды, с высокой и стабильной урожайностью [4]. Особенно велика потребность в сортах винограда очень раннего и раннего сроков созревания, с крупными и средними нарядными гроздями, отличающимися необычной формой и красивым цветом ягод, характеризующимися высокими вкусовыми качествами, а также в кишмишных сортах [5-7].

Требования к винным сортам винограда базируются на особенностях типов и марок вин, для приготовления которых они могут быть использованы [8-10]. В этих целях селекционерами АЗОСВиВ проводится большая работа, направленная на выведение новых высококачественных и урожайных технических сортов, адаптированных к местным природноклиматическим условиям, с высокими показателями продуктивности и качества, а также толерантных к опаснейшему вредителю - филлоксере.

Особенности селекции растений обусловлены успешным решением задач, которые перед ней стоят. Очень значимо изучение сортового, родового и видового разнообразия культур, влияния окружающей среды на развитие главных признаков, закономерностей наследования этих признаков для гибридизации, а также особенностей процесса селекции и стратегии искусственного отбора [11-15]. Каждый сорт растений приспособлен к каким-то определённым условиям, и поэтому в разных местностях существуют специализированные станции и хозяйства для проверки и сравнения новых сортов [16].

В настоящее время существует недостаток в сортименте сортов винограда технического направления использования. Возросший интерес к винному туризму диктует необходимость выращивания аборигенных сортов винограда и сортов местной селекции, их доля в реестре должна возрастать. Всё это определяет основные задачи селекции сортов винограда: создание технических сортов, сочетающих высокое качество продукции и адаптивность к абиотическим и биотическим стрессовым факторам, выве- 
Плодоводство и виноградарство Юга России № 60(6), 2019 г.

дение сортов для выработки оригинальных вин, сортов с высоким уровнем сахаронакопления, раннего срока созревания. Изучение этого вопроса для Анапо-Таманской зоны актуально и представляет большой интерес.

Объекты и методы исследований. Научно-исследовательская работа по изучению гибридных форм винограда на комплекс хозяйственноценных селекционных признаков проводилась полевыми и лабораторными методами на ампелографической коллекции АЗОСВиВ [4, 16-24].

Система ведения кустов на коллекционном участке опытной станции - вертикальная шпалера. Формировка - штамбовая, кордонная и по типу «Спирального кордона АЗОС-1». Площадь питания - 3,5 x 2,0 м. Агротехника - общепринятая в виноградарстве. Почва - выщелоченный, перегнойно-карбонатный чернозём.

Фенологические наблюдения осуществлялись по общепринятой методике. Агробиологические учёты проводились в первой половине лета [25]. Учитывались: среднее количество глазков и зелёных побегов на куст, плодоносных побегов, соцветий, определялись: коэффициент плодоношения, коэффициент плодоносности и процент распускания глазков. Срок сбора урожая определялся органолептически и на основе пробных анализов. Химический анализ (массовая концентрация сахаров) проводился полевым рефрактометром, кислотность в соке ягод - методом титрования.

Обсужнение результатов. В 2018 году было продолжено изучение ранее выделенных в элиту перспективных гибридных форм винограда технического направления:

1) III - 59-49 (Ф/У «Джемете» $\mathrm{x}$ Красностоп анапский), форма технического направления, среднего срока созревания; грозди средние, по форме цилиндрические, средней плотности, массой160-180 г;

2) III - 62-20 (Ф/У Джемете х Ркацители), форма технического направления, среднего срока созревания; грозди средние, по форме 
цилиндрические, средней плотности, массой 120-140 г, ягоды средние округлой формы, зелёные с загаром, кожица средней плотности, мякоть сочная, вкус освежающий;

3) III - 62-23 (Ф/У Джемете х Рислинг рейнский), форма технического направления, среднего срока созревания; грозди средние, по форме цилиндрические, средней плотности, массой 180 г, ягода округлой формы, слегка овальная, зелёная, кожица плотная, мякоть мясисто-сочная, во вкусе терпкость;

4) III - 62-24 (Ф\У Джемете х Каберне Совиньон), форма технического направления, ранне-среднего срока созревания; листья средние, пятилопастные, средне-сильно рассечённые, имеют округлую форму, верхняя поверхность тёмно-зелёная, пузырчатость отсутствует или очень слабая, нижняя поверхность имеет среднее щетинистое опушение, зубчики на концах лопастей средней длины с вогнутыми сторонами, черешковая выемка закрытая, черешок равен главной жилке листа. Грозди средние, конической формы, по плотности рыхлые с длинной плодоножкой, массой 180200 г; ягоды средние, округлой формы, темно-синие, кожица тонкая, но прочная, мякоть сочная; вкус отсутствует, рост кустов сильный.

5) К-1-74-1 - элитная гибридная форма технического направления среднего срока созревания; коэффициент плодоношения - 1,0 при среднем весе грозди 218,5 г; урожайность с куста 13,6 кг;

6) К-1-17-10 - элитная гибридная форма технического направления позднего срока созревания; коэффициент плодоношения - 0,5 при среднем весе грозди 230,5 г; урожайность с куста 7,5 кг.

Изучение агробиологических, фенологических и технологических особенностей позволило выделить данные элитные гибридные формы как наиболее урожайные и с высоким качеством продукции.

На гибридном участке ежегодно проводятся фенологические наблюдения. Это одна из важных форм работы исследователей при выполнении наблюдений на винограднике, так как все агротехнические мероприятия по 
Плодоводство и виноградарство Юга России № 60(6), 2019 г.

выращиванию винограда тесно связаны с прохождением отдельных фаз вегетации и покоя (табл. 1), что в свою очередь необходимо учитывать в селекционном процессе и выделении элитных гибридных форм по срокам созревания.

Таблица 1 - Фенологические наблюдения элитных гибридных форм винограда селекции АЗОСВиВ технического направления, 2018 г.

\begin{tabular}{|c|c|c|c|c|c|c|}
\hline 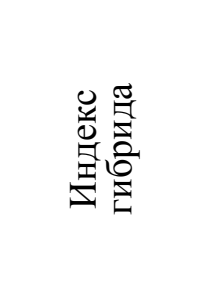 & 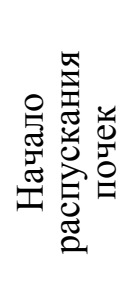 & 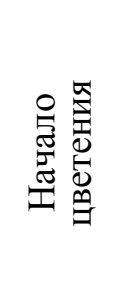 & 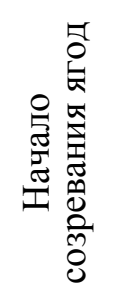 & 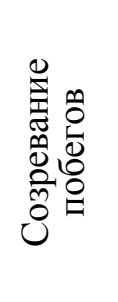 & 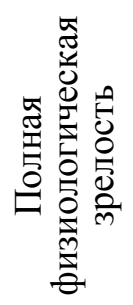 & 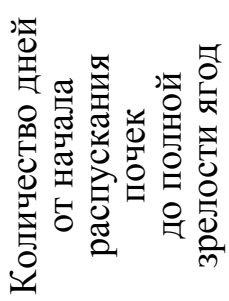 \\
\hline III-62-20 & 16.04 & 23.05 & 15.07 & 16.08 & 03.09 & 140 \\
\hline III $-62-21$ & 18.04 & 23.05 & 15.07 & 15.08 & 06.09 & 141 \\
\hline III- $62-23$ & 22.04 & 24.05 & 16.07 & 15.08 & 07.09 & 138 \\
\hline III-62-24 & 13.04 & 22.05 & 16.07 & 14.08 & 03.09 & 143 \\
\hline III-59-24 & 17.04 & 24.05 & 14.07 & 16.08 & 29.08 & 134 \\
\hline III-59-49 & 18.04 & 23.05 & 15.07 & 16.08 & 29.08 & 133 \\
\hline K-I-74-1 & 19.04 & 24.05 & 17.07 & 17.08 & 08.09 & 142 \\
\hline K-II-17-10 & 19.04 & 23.05 & 13.07 & 13.08 & 03.09 & 137 \\
\hline
\end{tabular}

Время и продолжительность прохождения виноградом различных фаз в значительной степени зависит от климатических условий местности. Поэтому чтобы иметь данные о сроках и времени прохождения фаз, необходимо проводить фенологические наблюдения за виноградными кустами, отмечая начало и конец каждой фазы, влияние на их прохождение погодных условий. Погодные условия весны в 2018 году несколько отличались от предыдущего года, что отразилось на ранних фазах вегетации, а также на дальнейшем развитии виноградного растения.

Из фенологических данных следует, что в 2018 году начало распускания почек прошло с 13.04 по 22.04. Цветение проходило с 22.05 по 24.05, при благоприятных условиях, на 2 недели раньше, чем в 2017 году - в третьей декаде мая (температура воздуха днём достигала $\left.+20,4{ }^{\circ} \mathrm{C}\right)$. Во время цветения наблюдалось незначительное выпадение осадков, но это не отразилось на цветении и опылении виноградного растения. 
Таблица 2 - Агробиологические показатели элитных гибридных форм винограда технического направления, 2018 год

\begin{tabular}{|c|c|c|c|c|c|c|c|c|c|c|c|c|c|}
\hline 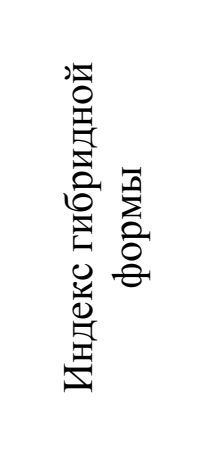 & 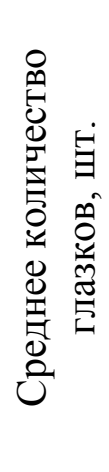 & 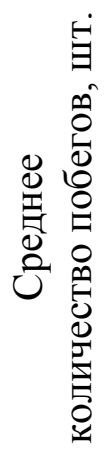 & 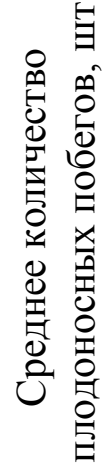 & 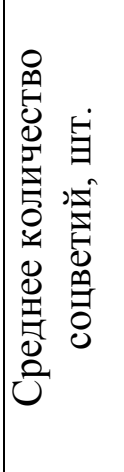 & 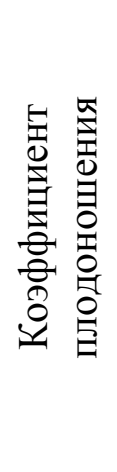 & 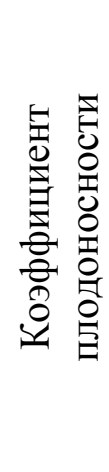 & 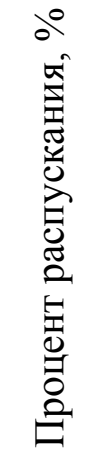 & 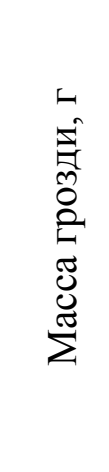 & 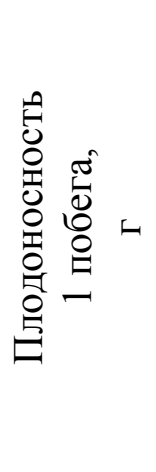 & 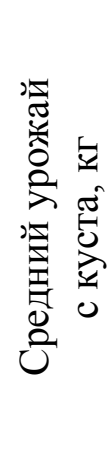 & 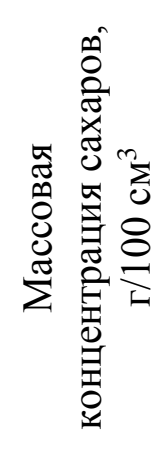 & 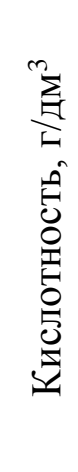 & 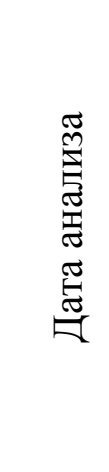 \\
\hline III-59-24 & 59,0 & 39,0 & 28,0 & 41,0 & 1,1 & 1,1 & 66,1 & 180,0 & 198,0 & 8,1 & 17,8 & 5,7 & 06.09 \\
\hline III-59-49 & 56,0 & 43,0 & 21,0 & 24,0 & 0,5 & 1,0 & 78,0 & 168,0 & 84,0 & 4,0 & 19,0 & 7,5 & 30.08 \\
\hline III-62-20 & 63,0 & 54,0 & 32,0 & 39,0 & 0,7 & 1,2 & 85,7 & $\overline{170,0}$ & 119,0 & 6,6 & 17,6 & 7,0 & 03.09 \\
\hline III-62-21 & 57,0 & 46,0 & 29,0 & 39,0 & 0,8 & 1,3 & 80,7 & 188,0 & 150,4 & 7,3 & 19,8 & 6,4 & 06.09 \\
\hline III-62-23 & 46,0 & 37,0 & 28,0 & 37,0 & 1,0 & 1,3 & 80,4 & 200,0 & 200,0 & 7,4 & 18,6 & 7,9 & 07.09 \\
\hline III-62-24 & 69,0 & 61,0 & 39,0 & 45,0 & 0,7 & 1,1 & 80,3 & 183,0 & 128,1 & 8,2 & 20,1 & 7,8 & 06.09 \\
\hline K-I-74-1 & 63,4 & 60,3 & 58,0 & 62,5 & 1,0 & 1,0 & 95,1 & 218,5 & 218,5 & 13,6 & 19,5 & 7,0 & 08.09 \\
\hline K-II-17-10 & 68,5 & 57,0 & 27,5 & 30,5 & 0,5 & 1,1 & 83,2 & 230,5 & 115,0 & 7,3 & 18,3 & 7,2 & 11.09 \\
\hline
\end{tabular}


Плодоводство и виноградарство Юга России № 60(6), 2019 г.

Полная физиологическая зрелость раньше всех была отмечена на элитных гибридных формах технического направления III-59-24 и III-59-49 - 29 августа, а позже всех эта фаза вегетации - на элитной технической гибридной форме K-I-74-1. К уборке урожая приступили в первой декаде августа, раньше обычных сроков, при жаркой и сухой погоде.

Проведён анализ агробиологических показателей изучаемых элитных гибридных форм винограда (табл. 2). Установлено, что самый низкий коэффициент плодоношения у гибридной формы III-59-49 и К-II-17-10 $(0,5)$, а самый высокий - у III-59-24 - 1,1. Коэффициент плодоносности всех изучаемых элитных гибридных форм технического направления колеблется в пределах от 1,1 до 1,3, при этом самый низкий он у форм III-59-49 и K-I-74-1, а самый высокий - у III-62-21 и III-62-23. Средний урожай с куста максимален у элитной гибридной технической формы K-I-74-1; плодоносность одного побега самая высокая у форм К-I-74-1, III-59-24 и III-62-23; самыми крупными гроздями (по массе) отличились формы К-II-17-10, K-I-74-1, III-62-23.

В результате биохимического анализа ягод исследуемых элитных гибридных технических форм винограда установлено, что наибольшая концентрация сахара в ягодах у форм III-62-24, III-62-21, K-I-74-1. Самая низкая кислотность сока ягод - у элитной гибридной формы III-62-21.

Заключение. Проведённое научное исследование комплекса хозяйственно ценных селекционных признаков у элитных гибридных форм винограда технического направления среднего и позднего сроков созревания выявило ряд особенностей. Элитная гибридная форма III-59-24 выделяется среди остальных исследуемых форм по среднему урожаю ягод с куста (при относительно небольшом среднем количестве плодоносных побегов на кусте) $-8,1$ кг, а также высоким коэффициентам плодоношения и плодоносности $-1,1$ и низкой кислотностью ягод $-5,7$ г/дм³. Элитная гибридная форма III-62-24 отличается средней урожайностью с куста - 8,2 кг, высо- 
Плодоводство и виноградарство Юга России № 60(6), 2019 г.

ким коэффициентом плодоносности - 1,1 и высоким содержанием сахара в ягодах - 20,1 г/100 см³. Элитная гибридная форма K-I-74-1 обладает самыми крупными гроздями, наибольшей урожайностью с одного куста, высокой концентрацией сахара в ягодах, наибольшей плодоносностью одного побега и массой грозди.

Данные элитные гибридные формы винограда будут изучаться и далее по вышеперечисленным хозяйственно ценным селекционным, агробиологическим, фенологическим и технологическим признакам.

\section{Литература}

1. Лазаревский М.А. Изучение сортов винограда. Ростов н/Д: Ростовский университет. $1963.151 \mathrm{c.}$

2. Айвазян П.К., Докучаева Е.Н. Селекция виноградной лозы. Киев: Украинская академия сельскохозяйственных наук. 1960. 344 с.

3. Кравченко Л.В. Научное обеспечение устойчивого ведения отрасли виноградарства. Новочеркасск: ВНИИВиВ. 2005. С. 13-14.

4. Недов П.Н. Новые методы фитопатологических и иммунологических исследований в виноградарстве. - Кишинёв: Штиица. 1985. 139 с.

5. Alleweldt G. Die Resistenzzüchtung von Reben. Rebe Wein. 1985, P. 75-77.

6. Alleweldt, G. The genetic resources of Vitis / G. Alleweldt, E. Dettweiler Siebeldingen. FRG, 1994. - $74 \mathrm{~s}$.

7. Bouquet, A. V. vinifera $x$ Muscadinia hybridization: A new way in grape breeding for disease resistance in France. Proc. 3rd Intern. Symp. Grape Breeding, Davis. 1980, P. 42-51.

8. Galet P. Dictionnaire encycloperdique des cer pages / P. Galet - Hachette. 2000. $936 \mathrm{p}$.

9. Gerdemann-Knorck, M. Utilization of assymmetric somatic hybridization for the transfer of disease resistance from Brassica nigra to Brassica napus / M. Gerdemann-Knorck, M.D. Sacristan, C. Breeding // Pestic. Outlook. - 1993. - №4. - P. 22 - 25.

10. Heuertz, M., Goryslavets, S., Hausman, J.F., Risovanna V. Characterization of grapevine accessions from Ukraine using microsatellite markers // American Journal of Enology and Viticulture. - 2008. - V. 59. - P. 38 - 42.

11. Lefort, F., Massa M., Goryslavets S., Risovanna V. and Troshin L. Genetic profiling of Moldavian, Crimean and Russian cultivars of Vitis vinifera L., with nuclear microsatellite markers // In: Ocnologie. - Paris: Editions Tec and Doc., 2003. - P.71 - 73.

12. Moore, J.N. «Relains» seediess grape. Hort. Science. - Vol.18. - P. 963.

13. Newton R. Molecular and physiological genetics of drought tolerance in forest species / R.J. Newton, E.A. Funkhouser, F. Fong, C.G. Tauer // Forest Ecology and Management. - 1991. - N 43. - P. $225-250$.

14. Cuharschi, M., Cebanu, V. Optimizarea tehnologiei de cultivare a viţei de vie în condiţiile Republicii Moldova // Viticultura şi Vinificaţia în Moldova. - 2006. - N 5. -P. 8-10.

15. Savin, Gh. Crearea şi implementarea soiurilor de viţă de vie cu diferit grad de apirenie, utilizare diversă şi rezistenţa sporită la factorii abiotici. I.N.V.V // Teze ale conferinţei ştiinţifice internaţionale // Aspecte inovative în viticultură şi vinificaţie-Chişinău, 2005. - P.21-24. 
16. Методика проведения испытания на отличимость, однородность и стабильность. Виноград RTG/0050/2 [Электронный ресурс]. 2000. URL: https://gossort.com/16organizaciya-i-provedenie-ispytaniy.html

17. Ларькина М.Д., Никулушкина Г.Е., Никольский М.А. Основные методы селекции винограда: учебно-методическое пособие по дисциплине «селекция и генетика овощных, плодовых культур и винограда» для студентов заочной и очной форм обучения направления подготовки 110500.62 «Садоводства» квалификационная (степень) «Бакалавр», Анапский филиал ФГБОУ ВПО КубГАУ. Краснодар: Издательский Дом Юг, 2015. 40 c.

18. Методическое и аналитическое обеспечение организации и проведения исследований по технологии производства винограда / Под ред. К.А. Серпуховитиной. Краснодар, 2010. 182 с.

19. Погосян С.А. Методические указания по селекции винограда. Ереван: Айастан, 1974. 226 с.

20. Программа Северокавказского центра по селекции плодовых, ягодных, цветочно-декоративных культур и винограда на период до 2030 года / под ред. Е.А. Егорова. Краснодар: ГНУ СКЗНИИСиВ, 2013. 202 с.

21. Регель Р.Э. Научные основы селекции в связи с предусматриванием константности форм по морфологическим признакам // Тр. 1-го съезда деятелей по селекции сельскохозяйственных растений. вып. 4. Харьков, 1911. С. 13.

22. Система виноградарства Краснодарского края. Методические рекомендации / Е.А. Егоров, И.А. Ильиной, К.А. Серпуховитина и др. Краснодар: ГНУ СКЗНИИСиВ, 2007. 125 c.

23. Современные методологические аспекты организации селекционного процесса в садоводстве и виноградарстве / под ред. акад. Г.В. Еремина. Краснодар: СКЗНИИСиВ, 2012. 569 с.

24. Современные методология, инструментарий оценки и отбора селекционного материала садовых культур и винограда / под ред. Е.А. Егорова. Краснодар: ФГБНУ СКФНЦСВВ, 2017. 282 с.

25. Агротехнические исследования по созданию интенсивных виноградных насаждений на промышленной основе ВНИИВиВ им. Я.И. Потапенко / Под ред. Б.А. Музыченко. Новочеркасск, 1978. 168 с.

\section{References}

1. Lazarevskij M.A. Izuchenie sortov vinograda. Rostov n/D: Rostovskij universitet. 1963. $151 \mathrm{~s}$.

2. Ajvazyan P.K., Dokuchaeva E.N. Selekciya vinogradnoj lozy. Kiev: Ukrainskaya akademiya sel'skohozyajstvennyh nauk. 1960. $344 \mathrm{~s}$.

3. Kravchenko L.V. Nauchnoe obespechenie ustojchivogo vedeniya otrasli vinogradarstva. Novocherkassk: VNIIViV. 2005. S. 13 - 14.

4. Nedov P.N. Novye metody fitopatologicheskih i immunologicheskih issledovanij v vinogradarstve. - Kishinyov: Shtiica. 1985. 139 s.

5. Alleweldt G. Die Resistenzzüchtung von Reben. Rebe Wein. 1985, P. 75-77.

6. Alleweldt, G. The genetic resources of Vitis / G. Alleweldt, E. Dettweiler Siebeldingen. FRG, 1994. - 74 s.

7. Bouquet, A. V. vinifera $x$ Muscadinia hybridization: A new way in grape breeding for disease resistance in France. Proc. 3rd Intern. Symp. Grape Breeding, Davis. 1980, P. $42-51$.

8. Galet P. Dictionnaire encycloperdique des cer pages / P. Galet - Hachette. 2000. $936 \mathrm{p}$. 
9. Gerdemann-Knorck, M. Utilization of assymmetric somatic hybridization for the transfer of disease resistance from Brassica nigra to Brassica napus / M. Gerdemann-Knorck, M.D. Sacristan, S. Breeding // Pestic. Outlook. - 1993. - №4. - P. 22 - 25.

10. Heuertz, M., Goryslavets, S., Hausman, J.F., Risovanna V. Characterization of grapevine accessions from Ukraine using microsatellite markers // American Journal of Enology and Viticulture. - 2008. - V. 59. - P. $38-42$.

11. Lefort, F., Massa M., Goryslavets S., Risovanna V. and Troshin L. Genetic profiling of Moldavian, Crimean and Russian cultivars of Vitis vinifera L., with nuclear microsatellite markers // In: Ocnologie. - Paris: Editions Tec and Doc., 2003. - P.71 - 73.

12. Moore, J.N. «Relains» seediess grape. Hort. Science. - Vol.18. - P. 963.

13. Newton R. Molecular and physiological genetics of drought tolerance in forest species / R.J. Newton, E.A. Funkhouser, F. Fong, C.G. Tauer // Forest Ecology and Management. - 1991. - N 43. - P. 225 - 250.

14. Cuharschi, M., Cebanu, V. Optimizarea tehnologiei de cultivare a viţei de vie în condiţiile Republicii Moldova // Viticultura şi Vinificaţia în Moldova. - 2006. - N 5. - P. 8-10.

15. Savin, Gh. Crearea şi implementarea soiurilor de viţă de vie cu diferit grad de apirenie, utilizare diversă şi rezistenţa sporită la factorii abiotici. I.N.V.V // Teze ale conferinţei ştiinţifice internaţionale // Aspecte inovative în viticultură şi vinificaţie-Chişinău, 2005. - R.21-24.

16. Metodika provedeniya ispytaniya na otlichimost', odnorodnost' i stabil'nost'. Vinograd RTG/0050/2 [Elektronnyj resurs]. 2000. URL: https://gossort.com/16-organizaciyai-provedenie-ispytaniy.html

17. Lar'kina M.D., Nikulushkina G.E., Nikol'skij M.A. Osnovnye metody selekcii vinograda: uchebno-metodicheskoe posobie po discipline «selekciya i genetika ovoshchnyh, plodovyh kul'tur i vinograda» dlya studentov zaochnoj i ochnoj form obucheniya napravleniya podgotovki 110500.62 «Sadovodstva» kvalifikacionnaya (stepen') «Bakalavr», Anapskij filial FGBOU VPO KubGAU. Krasnodar: Izdatel'skij Dom - Yug, 2015. $40 \mathrm{~s}$.

18. Metodicheskoe i analiticheskoe obespechenie organizacii i provedeniya issledovanij po tekhnologii proizvodstva vinograda / Pod red. K.A. Serpuhovitinoj. Krasnodar, 2010. $182 \mathrm{~s}$.

19. Pogosyan S.A. Metodicheskie ukazaniya po selekcii vinograda. Erevan: Ajastan, 1974. $226 \mathrm{~s}$.

20. Programma Severokavkazskogo centra po selekcii plodovyh, yagodnyh, cvetochno-dekorativnyh kul'tur i vinograda na period do 2030 goda / pod red. E.A. Egorova. Krasnodar: GNU SKZNIISiV, 2013. 202 s.

21. Regel' R.E. Nauchnye osnovy selekcii v svyazi s predusmatrivaniem konstantnosti form po morfologicheskim priznakam // Tr. 1-go s"ezda deyatelej po selekcii sel'skohozyajstvennyh rastenij. vyp. 4. Har'kov, 1911. S. 13.

22. Sistema vinogradarstva Krasnodarskogo kraya. Metodicheskie rekomendacii / E.A. Egorov, I.A. Il'inoj, K.A. Serpuhovitina i dr. Krasnodar: GNU SKZNIISiV, 2007. 125 s.

23. Sovremennye metodologicheskie aspekty organizacii selekcionnogo processa $\mathrm{v}$ sadovodstve i vinogradarstve / pod red. akad. G.V. Eremina. Krasnodar: SKZNIISiV, 2012. 569 s.

24. Sovremennye metodologiya, instrumentarij ocenki i otbora selekcionnogo materiala sadovyh kul'tur i vinograda / pod red. E.A. Egorova. Krasnodar: FGBNU SKFNCSVV, 2017. $282 \mathrm{~s}$.

25. Agrotekhnicheskie issledovaniya po sozdaniyu intensivnyh vinogradnyh nasazhdenij na promyshlennoj osnove VNIIViV im. Ya.I. Potapenko / Pod red. B.A. Muzychenko. Novocherkassk, 1978. 168 s. 